\title{
Analytical solution for the pull-out response of FRP rods embedded in steel tubes filled with cement grout
}

\author{
Zhimin Wu Shutong Yang · Jianjun Zheng \\ Xiaozhi Hu
}

Received: 4 June 2008/Accepted: 19 June 2009/Published online: 1 July 2009

(C) The Author(s) 2009. This article is published with open access at Springerlink.com

\begin{abstract}
Fiber-reinforced plastic (FRP) tendons have been widely used for ground anchors in civil engineering. Although various pull-out tests of FRP rods from grout-filled steel tubes have been conducted to simulate ground anchors in rock, there are relatively few theoretical studies reported in the literature for this type of bonded anchorages. The intention of this paper is to present an analytical solution for predicting the maximum pull-out load of FRP rods embedded in steel
\end{abstract}

\section{Z. Wu $\cdot$ S. Yang}

State Key Laboratory of Coastal and Offshore Engineering,

Dalian University of Technology, Dalian 116024,

People's Republic of China

$\mathrm{Z} . \mathrm{Wu}$

e-mail: zhiminwu2002@yahoo.com.cn

S. Yang $(\bowtie)$

School of Civil Engineering and Architecture,

Shandong University of Science and Technology,

Qingdao 266510, People's Republic of China

e-mail: yangshutong1979@yahoo.com.cn

\section{J. Zheng}

School of Civil Engineering and Architecture,

Zhejiang University of Technology, Hangzhou 310014,

People's Republic of China

e-mail: jjzheng@zjut.edu.cn

\section{Hu}

Department of Mechanical and Materials Engineering, University of Western Australia, Nedlands, Perth, WA 6907, Australia

e-mail: xhu@mech.uwa.edu.au tubes filled with cement grout. First, the expression of the shear stress along the thickness direction of the grout layer is obtained analytically. The tensile stress in the rod and the interfacial shear stress at the rodgrout interface are formulated at different loading stages. By modeling interfacial debonding as an interfacial shear crack, the pull-out load is then expressed as a function of the interfacial crack length. Finally, based on the Lagrange multiplier method, the maximum pull-out load and the critical crack length are determined. The validity of the proposed analytical solution is verified with the experimental results obtained from literature. It can be concluded that the proposed analytical solution can predict the maximum pull-out load of spiral wound and indented rods embedded in steel tubes filled with cement grout with reasonable accuracy. The proposed solution can be also applied in predicting the pull-out capacity of steel bars from concrete.

Keywords FRP rod - Cement grout .

Steel tube $\cdot$ Anchorage $\cdot$ Maximum pull-out load

\section{Introduction}

Fiber-reinforced plastic (FRP) rods are regarded as a better alternative to steel bars due to their high strength-to-weight ratio, resistance to corrosion, and ease of transportation and handling. Integrating fiber optic sensors into the FRP rods allows us to monitor 
the behavior of anchors satisfactorily [33]. As the FRP rod is widely used in ground anchorages such as grouted anchors embedded in rock, the bond properties between the FRP rod and cement grout have gradually attracted more attention of researchers and engineers.

Erki and Rizkalla [9, 10] introduced detailed anchorages for glass FRP (GFRP) and carbon FRP (CFRP) tendons, aramid fiber ropes and aramid FRP (AFRP) rods giving due considerations of their characteristics. These types of anchorages deserve more attention in practical applications due to the high axialto-lateral strength of FRP materials [22]. The bonded anchorage is one of the currently-used methods for FRP rods, in which a FRP rod is bonded into a steel pipe or tube filled with cement or resin grout [32]. The steel pipe or tube acts as an infinite rock mass [30]. Pull-out tests of FRP rods from grout-filled steel tubes are generally carried out to simulate the ground anchors in rock [5, 7, 22, 27, 30, 32, 33]. Mckay and Erki [22] found that the performance of cement grouted anchors depends on the confinement, moist curing and stiffness properties of the grout. Budelmann et al. [7] investigated the fatigue behavior of FRP bars anchored in a cylindrical steel tube filled with a quartz sand mortar. The introduction of sand and swelling agent into grout can create pressure on the rod and therefore increase the shear bonding resistance $[5,22,23]$. On the other hand, the shrinkage of cement grout decreases the shear strength [5, 32]. The load-bearing capacity of the anchorage increases as the bonding length and compressive strength of cement grout, and the elastic modulus of the steel sleeve increase $[3,5,8]$. If the steel sleeve too large, however, the effect of its stiffness becomes less significant [2]. Different surface geometries and mechanical properties of FRP rods can yield different bonding resistances and pull-out properties $[6,30]$. Moreover, the multi-grouted anchor has been recommended for practical engineering applications due to its higher stiffness and load-bearing capacity than the single grouted anchor [33]. Zhang et al. [34] carried out a test on a full-scale ground anchor with fiber-reinforced polymeric 9-bar tendons and found that the tendons perform satisfactorily in post-tensioning applications. Benmokrane et al. [4] replaced steel tubes with concrete in laboratory tests and with rock in field tests as host media for pull-out tests. Results showed that the bond strength from the laboratory tests is higher than that from the field tests.
Although much experimental work has been carried out on grouted FRP bars anchored in mortar-filled steel tubes, theoretical studies are relatively few in the literature. Zhang et al. [32] presented an analytical model for predicting the tensile capacity of bonded anchorages. In their model, four parameters related to the FRP rod-grout interface, as well as the distribution of the bond stress along the embedment length in the ultimate state, are required to write equilibrium equations. The theoretical results are in good agreement with the test results.

Since FRP rods are a possible replacement of steel bars, current studies for pull-out of metallic bars from cementitious matrix can provide some references on the bonding characteristics between the FRP rod and cement grout. The interaction between the bar and concrete is generally characterized by four different stages [11]. At the first stage, bond efficiency is assured by chemical adhesion without any slip. Then the chemical adhesion breaks down, and interfacial slip occurs. The bond strength and stiffness are assured mostly by the interlocking among the reinforcements at the following stage. Finally, splitting-induced pullout failure or single pull-out failure occurs depending on the transverse confinement or the thickness of the concrete cover. Li et al. [20] introduced two methods to improve the bond properties by modifying the matrix and the rebar surface. Results showed that both methods can (a) improve the bond performance, (b) increase the interfacial microhardness and (c) reduce the porous region of the interface. Bamonte et al. [1] investigated the size effect of bonding of anchorages to ordinary and high performance concrete, and found that the bond is less size-dependent in high performance concrete due to the greater tensile strength, homogeneity and chemical adhesion with the bar.

Moreover, the models for pull-out of fibers from matrix provide some theoretical guidance. A shearlag model was frequently applied in theoretical studies, in which the tensile stresses in the matrix are negligible compared with those in the fiber [13]. Based on this model, the behavior of the composites before and after debonding was extensively analyzed [14-19, 29]. The fracture energy-based criterion [12, $17,19,24,28,29]$ was used to describe the interfacial debonding behavior. The advantages of this criterion were detailedly discussed by Stang et al. [29]. Zhang et al. [31] presented an improved model to obtain the stress fields in both bonded and debonded regions at 
the fiber-matrix interface by considering a pull-out rate-dependent frictional coefficient. The whole process of pulling out a single fiber was then modeled numerically [21]. Naaman and Namur et al. [25, 26] accurately obtained the entire pull-out load-end slip relationship of fibers using a dynamic mechanism, in which the Poisson's effect, shrink-fit and fiber-matrix misfit theory were incorporated.

Based on the pioneer work by Zhang et al. [32], an analytical solution is proposed in this paper for the maximum pull-out load of FRP rods embedded in steel tubes filled with cement grout. One advantage of the proposed solution is that no assumption is made on the bond stress distribution along the embedment length. Finally, the validity of the proposed solution is verified against some experimental results obtained from the literature.

\section{The maximum pull-out load of FRP rods}

\subsection{Basic assumptions}

According to the setup of a typical pull-out test given in the previous studies [5, 30], a simplified model is proposed for a cement-grouted FRP rod anchored in a steel tube as shown in Fig. 1, where $D$ denotes the rod diameter, $t$ the grout layer thickness, $b$ the tube thickness, $L$ the embedment length, $P$ the pull-out load, and $q$ the uniform force acting on the top surface of the steel tube. The assumptions used for the analytical solution are as follows:

a. The cement grout and steel tube are both linear elastic materials with Young's moduli $E_{\mathrm{c}}$ and $E_{\mathrm{s}}$, respectively.

b. The bond between the tube and grout is perfect, i.e., there is no shear slip, elastic slip or debonding at the interface.

c. The normal stress is uniform on the cross-section of the steel tube.

d. The grout with shear modulus $G$ is in a state of pure shear.

e. Based on the experimental results from Zhang and Benmokrane [30], the relationship between the shear stress $\tau$ and slip $\delta$ at the rod-grout interface is multi-linear as shown in Fig. 2. The grout sleeve is modeled as a shear-lag member, whose shear stiffness $k$ is equal to the slope of the ascending portion in the $\tau-\delta$ curve. Thus, the relationship is given by

$$
\begin{aligned}
\tau & =k \delta \quad\left(0 \leq \delta \leq \delta_{1}\right) \\
\tau & =\frac{\tau_{u} \delta_{2}-\tau_{s} \delta_{1}}{\delta_{2}-\delta_{1}}-\frac{\tau_{u}-\tau_{s}}{\delta_{2}-\delta_{1}} \delta \quad\left(\delta_{1}<\delta \leq \delta_{2}\right) \\
\tau & =\tau_{s} \quad\left(\delta>\delta_{2}\right),
\end{aligned}
$$

where $\tau_{\mathrm{u}}$ and $\tau_{\mathrm{s}}$ are the shear strength and residual frictional stress at the rod-grout interface, respectively.
Fig. 1 Stress distribution and geometrical dimensions of simplified anchorage specimen

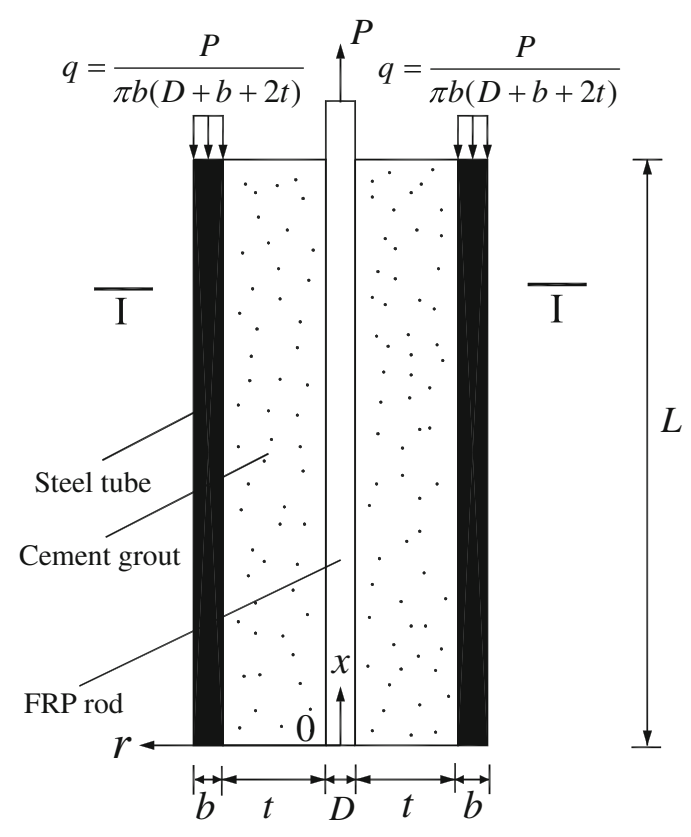




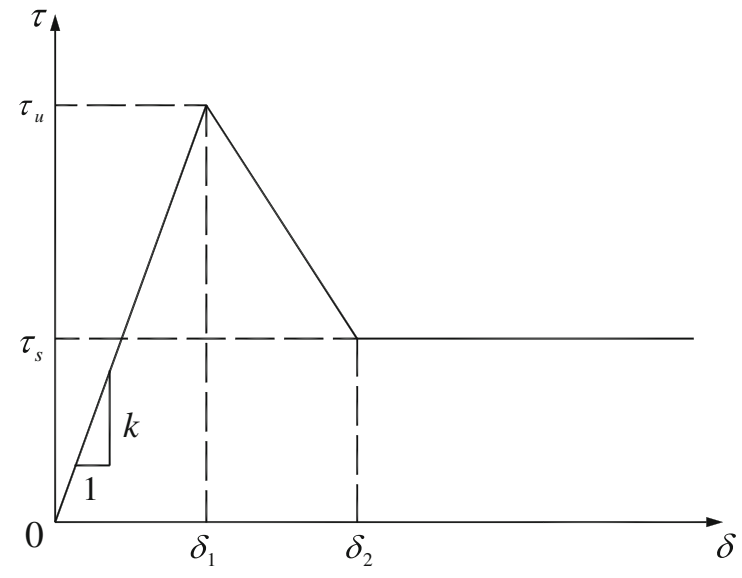

Fig. 2 Relationship between interfacial shear stress and slip

f. All radial effects of the rod, grout and steel tube are neglected.

g. Since the radial stiffness of the confining medium (i.e., the steel tube) is relatively large for this type of anchored FRP rods and the shear dilation of the grout is neglected, interfacial debonding at the rod-grout interface is the most likely failure mode.

\subsection{The numerical model}

A cylindrical rod element and a cylindrical grout shell element as shown in Fig. 3 are considered, where $\sigma_{\mathrm{p}}$ is the tensile stress in the rod and $\tau_{\mathrm{r}}$ is the shear stress in the grout layer at the distance $r$ from the $x$ axis. According to the principle of equilibrium

Fig. 3 Stress analysis of rod and grout elements

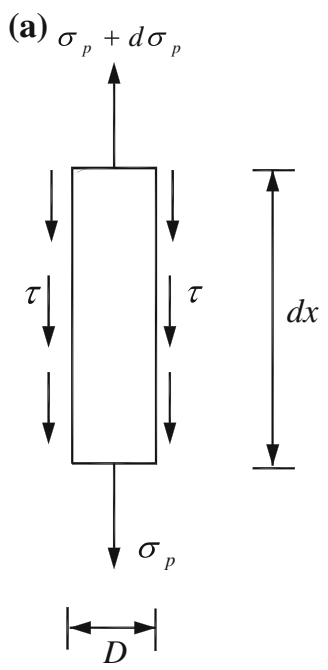

of forces shown in Fig. 3a, $\tau$ can be expressed in terms of $\sigma_{\mathrm{p}}$ as

$\tau=\frac{D}{4} \frac{d \sigma_{p}}{d x}$.

For the grout element shown in Fig. 3b, equilibrium yields

$\frac{1}{\tau_{r}} d \tau_{r}=-\frac{1}{r} d r$.

Solving Eq. 3, we have

$\tau_{r}=\frac{D}{2 r} \tau$.

If $u$ denotes the longitudinal displacement in the grout, $\tau_{\mathrm{r}}$ can be expressed as

$\tau_{r}=-G \frac{d u}{d r}$.

Substituting Eq. 4 into Eq. 5 and integrating $u$ with respect to $r$, we have

$u=u_{m}+\frac{D \tau}{2 G} \ln \frac{D}{2 r}$,

where $u_{\mathrm{m}}$ is the longitudinal displacement at the rodgrout interface. According to assumption (b), the longitudinal displacement $u_{\mathrm{s}}$ of the steel tube is equal to $u$ at $r=t+D / 2$, i.e.,

$u_{s}=u_{m}+\frac{D \tau}{2 G} \ln \frac{D}{D+2 t}$.

If $u_{\mathrm{p}}$ denotes the longitudinal displacement of the rod, the interfacial slip at the rod-grout interface is equal to

(b)

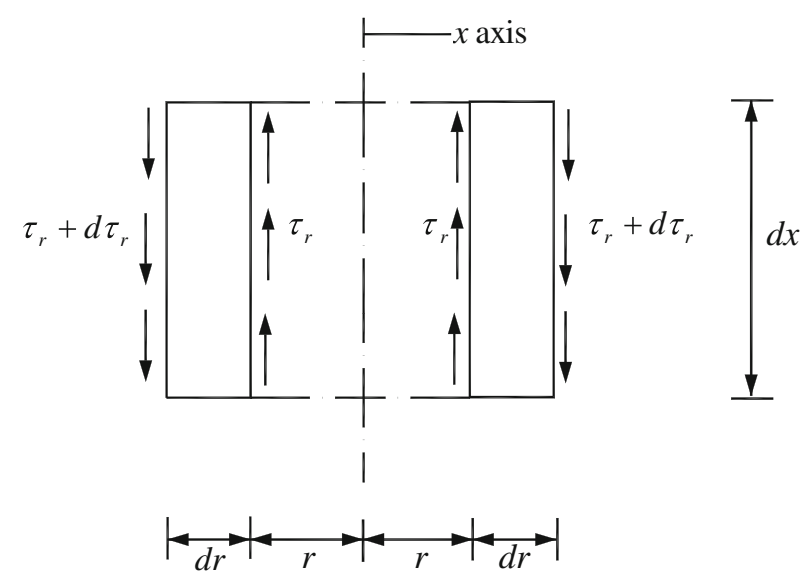


$\delta=u_{p}-u_{m}$.

When the rod-grout interface is in an elastic state, $\tau$ can be obtained by combining Eq. 1a with Eqs. 7 and 8 as follows

$\tau=\frac{2 k G}{2 G+D k \ln \frac{D+2 t}{D}}\left(u_{p}-u_{s}\right)$.

Differentiating $\tau$ with respect to $x$ yields

$\frac{d \tau}{d x}=\frac{2 k G}{2 G+D k \ln \frac{D+2 t}{D}}\left(\frac{\sigma_{p}}{E_{p}}-\frac{\sigma_{s}}{E_{s}}\right)$,

where $E_{\mathrm{p}}$ is the Young's modulus of the FRP rod and $\sigma_{\mathrm{s}}$ is the normal stress in the steel tube. According to the equilibrium of forces on the cross-section shown in Fig. 4, the relationship between $\sigma_{\mathrm{p}}$ and $\sigma_{\mathrm{s}}$ is

$\sigma_{s}=-\frac{D^{2}}{4 b(D+b+2 t)} \sigma_{p}$.

Substitution of Eqs. 2 and 11 into Eq. 10 yields

$\frac{d^{2} \sigma_{p}}{d x^{2}}-\alpha^{2} \sigma_{p}=0$

where

$\alpha^{2}=\frac{8 k G}{D\left(2 G+D k \ln \frac{D+2 t}{D}\right)}\left[\frac{1}{E_{p}}+\frac{D^{2}}{4 E_{s} b(D+b+2 t)}\right]$.

By introducing the following boundary conditions

$\sigma_{p}(x=0)=0$

Fig. 4 Normal stresses on the cross-section of the anchorage specimen
$\sigma_{p}(x=L)=\frac{4 P}{\pi D^{2}}$

$\sigma_{\mathrm{p}}$ and $\tau$ have the following expressions:

$\sigma_{p}=\frac{4 P}{\pi D^{2}} \frac{e^{\alpha x}-e^{-\alpha x}}{e^{\alpha L}-e^{-\alpha L}}$

$\tau=\frac{P \alpha}{\pi D} \frac{e^{\alpha x}+e^{-\alpha x}}{e^{\alpha L}-e^{-\alpha L}}$.

When $P$ is equal to the initial cracking load $P_{\text {ini }}, \tau$ at the loaded end (i.e., $x=L$ ) reaches the interfacial shear strength $\tau_{\mathrm{u}}$, i.e.,

$P_{\mathrm{ini}}=\frac{\tau_{u} \pi D}{\alpha} \frac{e^{\alpha L}-e^{-\alpha L}}{e^{\alpha L}+e^{-\alpha L}}$.

When $P$ continues to increase, an interfacial debonding region, referred to as the interfacial crack hereafter, will occur near the loaded end. According to the relationship between $\tau$ and $\delta$ shown in Fig. 2, there is a single interfacial crack, but two interfacial behaviors, with either softening or friction. Once $P>P_{\text {ini }}$, a softening crack of length $a_{\mathrm{s}}$ first appears at the loaded end as shown in Fig. 5.

Since the rod-grout interface of $0 \leq x \leq L-a_{\mathrm{s}}$ is still in an elastic state, $\sigma_{\mathrm{p}}$ and $\tau$ can be obtained by solving Eq. 12 and applying the conditions of Eq. 14 and $\tau\left(x=L-a_{\mathrm{s}}\right)=\tau_{\mathrm{u}}$ as follows

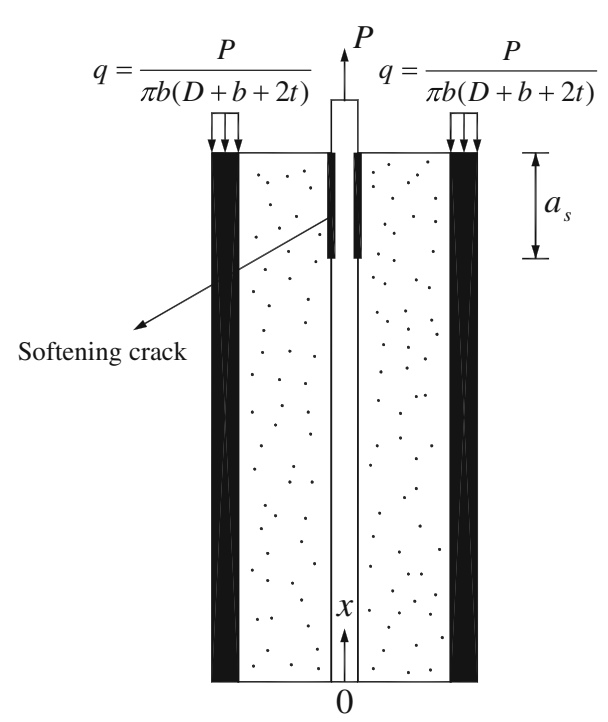

Fig. 5 Softening crack propagation along the rod-grout interface 


$$
\begin{aligned}
& \sigma_{p}=\frac{4 \tau_{u}}{D \alpha} \frac{e^{\alpha x}-e^{-\alpha x}}{e^{\alpha\left(L-a_{s}\right)}+e^{-\alpha\left(L-a_{s}\right)}} \\
& \tau=\tau_{u} \frac{e^{\alpha x}+e^{-\alpha x}}{e^{\alpha\left(L-a_{s}\right)}+e^{-\alpha\left(L-a_{s}\right)}} .
\end{aligned}
$$

In the region of $L-a_{\mathrm{s}}<x \leq L$, the interface is in a softening state. By combining Eq. $1 \mathrm{~b}$ with Eqs. 7 and $8, \tau$ is related to $u_{\mathrm{p}}$ and $u_{\mathrm{s}}$ by

$$
\begin{aligned}
\tau= & -\frac{2 G\left(\tau_{u}-\tau_{s}\right)}{2 G\left(\delta_{2}-\delta_{1}\right)+D\left(\tau_{u}-\tau_{s}\right) \ln \frac{D}{D+2 t}}\left(u_{p}-u_{s}\right) \\
& +\frac{2 G\left(\tau_{u} \delta_{2}-\tau_{s} \delta_{1}\right)}{2 G\left(\delta_{2}-\delta_{1}\right)+D\left(\tau_{u}-\tau_{s}\right) \ln \frac{D}{D+2 t}}
\end{aligned}
$$

Differentiating $\tau$ with respect to $x$ yields

$\frac{d \tau}{d x}=-\frac{2 G\left(\tau_{u}-\tau_{s}\right)}{2 G\left(\delta_{2}-\delta_{1}\right)+D\left(\tau_{u}-\tau_{s}\right) \ln \frac{D}{D+2 t}}\left(\frac{\sigma_{p}}{E_{p}}-\frac{\sigma_{s}}{E_{s}}\right)$.

Substituting Eqs. 2 and 11 into Eq. 22, we can obtain another differential equation as follows

$\frac{d^{2} \sigma_{p}}{d x^{2}}+\omega^{2} \sigma_{p}=0$,

where

$$
\begin{aligned}
\omega^{2}= & \frac{8 G\left(\tau_{u}-\tau_{s}\right)}{2 D G\left(\delta_{2}-\delta_{1}\right)+D^{2}\left(\tau_{u}-\tau_{s}\right) \ln \frac{D}{D+2 t}} \\
& {\left[\frac{1}{E_{p}}+\frac{D^{2}}{4 E_{s} b(D+b+2 t)}\right] . }
\end{aligned}
$$

By solving Eq. 23 and considering the continuity conditions of $\sigma_{\mathrm{p}}$ and $\tau$ at $x=L-a_{\mathrm{s}}, \sigma_{\mathrm{p}}$ and $\tau$ can be determined as follows

$$
\begin{aligned}
\sigma_{p}= & {\left[\frac{4 \tau_{u}}{D \alpha} \tanh \left(\alpha\left(L-a_{s}\right)\right) \cos \omega\left(L-a_{s}\right)\right.} \\
& \left.-\frac{4 \tau_{u}}{D \omega} \sin \omega\left(L-a_{s}\right)\right] \cos \omega x \\
& +\left[\frac{4 \tau_{u}}{D \alpha} \times \tanh \left(\alpha\left(L-a_{s}\right)\right) \sin \omega\left(L-a_{s}\right)\right. \\
& \left.+\frac{4 \tau_{u}}{D \omega} \cos \omega\left(L-a_{s}\right)\right] \sin \omega x
\end{aligned}
$$

$$
\begin{aligned}
\tau= & -\tau_{u}\left[\frac{\omega}{\alpha} \tanh \left(\alpha\left(L-a_{s}\right)\right) \cos \omega\left(L-a_{s}\right)\right. \\
& \left.-\sin \omega\left(L-a_{s}\right)\right] \sin \omega x \\
& +\tau_{u}\left[\frac{\omega}{\alpha} \times \tanh \left(\alpha\left(L-a_{s}\right)\right) \sin \omega\left(L-a_{s}\right)\right. \\
& \left.+\cos \omega\left(L-a_{s}\right)\right] \cos \omega x .
\end{aligned}
$$

By substituting Eq. 15 into Eq. 25, $P$ can be expressed in terms of $a_{\mathrm{s}}$ as follows

$P=\frac{\tau_{u} \pi D}{\alpha} \tanh \left(\alpha\left(L-a_{s}\right)\right) \cos \omega a_{s}+\frac{\tau_{u} \pi D}{\omega} \sin \omega a_{s}$.

When the ultimate state is reached, the critical softening crack length $a_{\mathrm{sc}}$ can be determined by solving $\mathrm{d} P / \mathrm{d} a_{\mathrm{s}}=0$ and the maximum pull-out load $P_{\max }$ is then obtained by inserting $a_{\text {sc }}$ into Eq. 27. The interfacial shear stress $\tau_{0}$ at the free end (i.e., the free end) can be obtained by inserting $x=0$ into Eq. 20 as follows

$\tau_{0}=\frac{2 \tau_{u}}{e^{\alpha\left(L-a_{s}\right)}+e^{-\alpha\left(L-a_{s}\right)}}$.

From Eq. 28a, it can be seen that $\tau_{0}$ is always smaller than $\tau_{\mathrm{u}}$, which shows that no interfacial debonding will occur at the free end. The interfacial shear stress $\tau_{\mathrm{L}}$ at the loaded end can be obtained by inserting $x=L$ and $a_{\mathrm{s}}=a_{\mathrm{sc}}$ into Eq. 26 as follows

$\tau_{L}=\tau_{u} \cos \omega a_{s c}-\frac{\tau_{u} \omega}{\alpha} \tanh \left(\alpha\left(L-a_{s c}\right)\right) \sin \omega a_{s c}$.

In Eq. $28 b, \tau_{\mathrm{L}}$ is larger than $\tau_{\mathrm{s}}$. When $\tau_{\mathrm{L}}$ is smaller than $\tau_{\mathrm{s}}$, a frictional crack of length $a_{\mathrm{f}}$ will develop at the loaded end before the ultimate state occurs as shown in Fig. 6.

For the region of $0 \leq x \leq L-a_{\mathrm{s}}-a_{\mathrm{f}}, \sigma_{\mathrm{p}}$ and $\tau$ are given by solving Eq. 12 and combining with Eq. 14 and $\tau\left(x=L-a_{\mathrm{s}}-a_{\mathrm{f}}\right)=\tau_{\mathrm{u}}$ as follows

$$
\begin{aligned}
& \sigma_{p}=\frac{4 \tau_{u}}{D \alpha} \frac{e^{\alpha x}-e^{-\alpha x}}{e^{\alpha\left(L-a_{s}-a_{f}\right)}+e^{-\alpha\left(L-a_{s}-a_{f}\right)}} \\
& \tau=\tau_{u} \frac{e^{\alpha x}+e^{-\alpha x}}{e^{\alpha\left(L-a_{s}-a_{f}\right)}+e^{-\alpha\left(L-a_{s}-a_{f}\right)}} .
\end{aligned}
$$

For the region of $L-a_{\mathrm{s}}-a_{\mathrm{f}}<x \leq L-a_{\mathrm{f}}, \sigma_{\mathrm{p}}$ and $\tau$ are obtained by solving Eq. 23 and considering the 


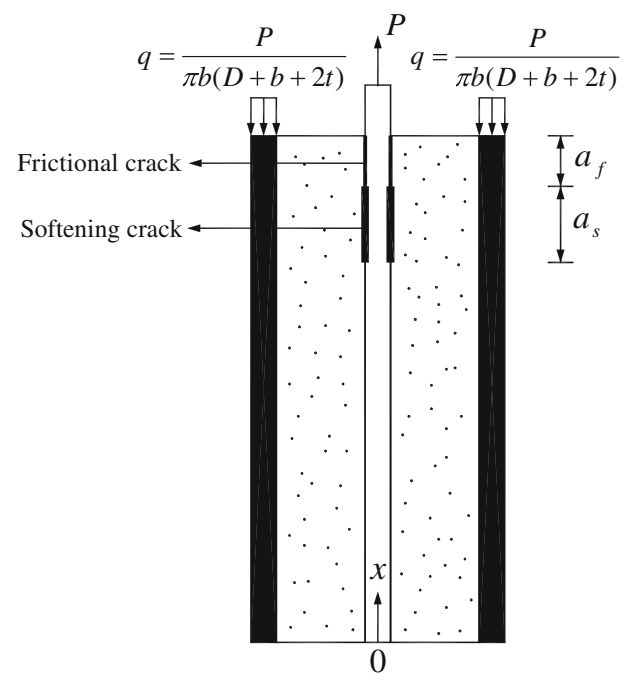

Fig. 6 Softening crack and frictional crack propagation along the rod-grout interface

continuity conditions of $\sigma_{\mathrm{p}}$ and $\tau$ at $x=L-a_{\mathrm{s}}-a_{\mathrm{f}}$ that

$$
\begin{aligned}
\sigma_{p}= & {\left[\frac{4 \tau_{u}}{D \alpha} \tanh \left(\alpha\left(L-a_{s}-a_{f}\right)\right) \cos \omega\left(L-a_{s}-a_{f}\right)\right.} \\
& \left.-\frac{4 \tau_{u}}{D \omega} \sin \omega\left(L-a_{s}-a_{f}\right)\right] \cos \omega x \\
& +\left[\frac{4 \tau_{u}}{D \alpha} \tanh \left(\alpha\left(L-a_{s}-a_{f}\right)\right) \sin \omega\left(L-a_{s}-a_{f}\right)\right. \\
& \left.+\frac{4 \tau_{u}}{D \omega} \cos \omega\left(L-a_{s}-a_{f}\right)\right] \sin \omega x \\
\tau= & -\tau_{u}\left[\frac{\omega}{\alpha} \tanh \left(\alpha\left(L-a_{s}-a_{f}\right)\right) \cos \omega\left(L-a_{s}-a_{f}\right)\right. \\
- & \left.\sin \omega\left(L-a_{s}-a_{f}\right)\right] \sin \omega x \\
& +\tau_{u}\left[\frac{\omega}{\alpha} \tanh \left(\alpha\left(L-a_{s}-a_{f}\right)\right) \sin \omega\left(L-a_{s}-a_{f}\right)\right. \\
& \left.+\cos \omega\left(L-a_{s}-a_{f}\right)\right] \cos \omega x .
\end{aligned}
$$

The continuity condition of $\tau\left(x=L-a_{\mathrm{f}}\right)=\tau_{\mathrm{s}}$ yields the following equation

$\cos \omega a_{s}-\frac{\omega}{\alpha} \tanh \left(\alpha\left(L-a_{s}-a_{f}\right)\right) \sin \omega a_{s}-\frac{\tau_{s}}{\tau_{u}}=0$.

For the frictional region of $L-a_{\mathrm{f}}<x \leq L, \tau$ is always equal to $\tau_{\mathrm{s}}$. Thus, another differential equation can be derived by using Eq. 2 as follows $\frac{d \sigma_{p}}{d x}=\frac{4 \tau_{s}}{D}$.

Solving Eq. 34 and considering the continuity condition of $\sigma_{\mathrm{p}}$ at $x=L-a_{\mathrm{f}}$, we have

$$
\begin{aligned}
\sigma_{p}= & \frac{4 \tau_{s}}{D} x+\frac{4 \tau_{u}}{D \alpha} \tanh \left(\alpha\left(L-a_{s}-a_{f}\right)\right) \cos \omega a_{s} \\
& +\frac{4 \tau_{u}}{D \omega} \sin \omega a_{s}-\frac{4 \tau_{s}}{D}\left(L-a_{f}\right) .
\end{aligned}
$$

By combining the boundary condition of Eq. 15 with Eq. 35, $P$ can be expressed in terms of $a_{\mathrm{s}}$ and $a_{\mathrm{f}}$ as follows

$$
\begin{aligned}
P= & \tau_{s} \pi D a_{f}+\frac{\tau_{u} \pi D}{\alpha} \tanh \left(\alpha\left(L-a_{s}-a_{f}\right)\right) \cos \omega a_{s} \\
& +\frac{\tau_{u} \pi D}{\omega} \sin \omega a_{s} .
\end{aligned}
$$

To obtain the maximum pull-out load $P_{\max }$, the Lagrange multiplier method is adopted in this paper. For this purpose, a Lagrange function $\Phi\left(a_{\mathrm{s}}, a_{\mathrm{f}}, \lambda\right)$ is constituted from Eqs. 33 and 36 as follows

$$
\begin{aligned}
\Phi\left(a_{s}, a_{f}, \lambda\right)= & \tau_{s} \pi D a_{f}+\frac{\tau_{u} \pi D}{\alpha} \tanh \left(\alpha\left(L-a_{s}-a_{f}\right)\right) \\
& \cos \omega a_{s}+\frac{\tau_{u} \pi D}{\omega} \sin \omega a_{s} \\
& +\lambda\left[\cos \omega a_{s}-\frac{\omega}{\alpha} \tanh \left(\alpha\left(L-a_{s}-a_{f}\right)\right)\right. \\
& \left.\sin \omega a_{s}-\frac{\tau_{s}}{\tau_{u}}\right]
\end{aligned}
$$

where $\lambda$ is an unknown parameter to be solved. By applying the following conditions

$\frac{\partial \Phi}{\partial a_{s}}=\frac{\partial \Phi}{\partial a_{f}}=\frac{\partial \Phi}{\partial \lambda}=0$

three equations can be established. By solving the three equations, the critical crack lengths $a_{\mathrm{sc}}$ and $a_{\mathrm{fc}}$, and the maximum pull-out load $P_{\max }$ can be determined.

\section{Experimental verification and discussion}

To verify the proposed analytical solution, some experimental results obtained from the literature are selected for comparison [32]. The basic parameters used in the analytical solution are shown in Table 1 . In the experiment of Zhang et al. [32], three types of FRP 
Table 1 Basic geometrical and mechanical parameters of anchorage specimens from Zhang et al. [32]

\begin{tabular}{|c|c|c|c|c|c|c|c|c|c|}
\hline No. & Type & $D(\mathrm{~mm})$ & $t(\mathrm{~mm})$ & $b(\mathrm{~mm})$ & $L(\mathrm{~mm})$ & $E_{\mathrm{c}}(\mathrm{GPa})$ & $\begin{array}{l}\text { Poisson's ratio } v \\
\text { of grout }\end{array}$ & $E_{\mathrm{p}}(\mathrm{GPa})$ & $E_{\mathrm{s}}(\mathrm{GPa})$ \\
\hline 1 & Round sanded + CG1 & 7.5 & 21.75 & 3.0 & 100 & 17.4 & 0.11 & 60.83 & 195 \\
\hline 2 & Round sanded + CG2 & 7.5 & 21.75 & 3.0 & 100 & 18.6 & 0.11 & 60.83 & 195 \\
\hline 3 & Round sanded + CG3 & 7.5 & 21.75 & 3.0 & 100 & 22.9 & 0.10 & 60.83 & 195 \\
\hline 4 & Round sanded + CG4 & 7.5 & 21.75 & 3.0 & 100 & 16.7 & 0.12 & 60.83 & 195 \\
\hline 5 & Round sanded + CG4 & 7.5 & 21.75 & 3.0 & 200 & 16.7 & 0.12 & 60.83 & 195 \\
\hline 6 & Round sanded + CG4 & 7.5 & 21.75 & 3.0 & 350 & 16.7 & 0.12 & 60.83 & 195 \\
\hline 7 & Spiral wound + CG1 & 8.0 & 21.50 & 3.0 & 100 & 17.4 & 0.11 & 43.50 & 195 \\
\hline 8 & Spiral wound + CG2 & 8.0 & 21.50 & 3.0 & 100 & 18.6 & 0.11 & 43.50 & 195 \\
\hline 9 & Spiral wound + CG3 & 8.0 & 21.50 & 3.0 & 100 & 22.9 & 0.10 & 43.50 & 195 \\
\hline 10 & Spiral wound + CG4 & 8.0 & 21.50 & 3.0 & 100 & 16.7 & 0.12 & 43.50 & 195 \\
\hline 11 & Spiral wound + CG4 & 8.0 & 21.50 & 3.0 & 200 & 16.7 & 0.12 & 43.50 & 195 \\
\hline 12 & Spiral wound + CG4 & 8.0 & 21.50 & 3.0 & 350 & 16.7 & 0.12 & 43.50 & 195 \\
\hline 13 & Indented + CG1 & 7.9 & 21.55 & 3.0 & 100 & 17.4 & 0.11 & 163.33 & 195 \\
\hline 14 & Indented + CG2 & 7.9 & 21.55 & 3.0 & 100 & 18.6 & 0.11 & 163.33 & 195 \\
\hline 15 & Indented + CG3 & 7.9 & 21.55 & 3.0 & 100 & 22.9 & 0.10 & 163.33 & 195 \\
\hline 16 & Indented + CG4 & 7.9 & 21.55 & 3.0 & 100 & 16.7 & 0.12 & 163.33 & 195 \\
\hline 17 & Indented + CG4 & 7.9 & 21.55 & 3.0 & 200 & 16.7 & 0.12 & 163.33 & 195 \\
\hline
\end{tabular}

Table 2 Mixture proportions of four grouts from Zhang et al. [32]

No. Mixture proportions

CG1 Type 10 portland cement (ASTM 1)

CG2 Type 30 portland cement (ASTM II) + superplasticizer solids ( $1 \%$ by weight of cement)

CG3 Type 10 portland cement (ASTM 1$)+$ sand (40\% by weight of cement)

CG4 Type SF cement (blended Type I cement containing 8\% silica fume $)+$ swelling agent $(0.004 \%$ by weight of cement and other additives)

rods, classified as round sanded, spiral wound and indented, and four types of cement grouts denoted as CG1, CG2, CG3 and CG4 were prepared and tested. The mixture proportions of the four grouts are shown in Table 2. In each test, the specimens with the embedment lengths of $100 \mathrm{~mm}(D=7.5,7.9$ and $8.0 \mathrm{~mm})$ were used to determine the interfacial parameters as shown in Table 3 [32]. The shear modulus $G$ of grout for each type of specimens can be calculated by

$G=\frac{E_{c}}{2(1+v)}$.

With these parameters, $P_{\max }^{\mathrm{a}}$ can be determined by applying the proposed analytical procedure, to make comparisons with the experimentally-measured $P_{\max }^{\mathrm{e}}$ as shown in Table 4.

It can be seen from Table 4 that, except for Nos. 5 and 6 specimens, the calculated results are in good agreement with the experimental results. For Nos. 5 and 6 specimens, the surface of FRP rods is round sanded and their embedment lengths are relatively long. The bond between the round sanded rod and grout mainly depends on chemical adhesion and friction once the interfacial slip occurs [30]. In addition, since the elastic modulus of the round sanded rod is relatively low $(60.83 \mathrm{GPa})$, the effect of the radial shrinkage in the rod becomes more significant due to the larger maximum pull-out strains. As a result, the interfacial shear strength $\tau_{\mathrm{u}}$ and residual frictional stress $\tau_{\mathrm{s}}$ decrease, which has not been taken into account in the proposed analytical solution. For other specimens, however, the bond between the spiral wound or indented rod and grout is mainly due to the interlocking interaction. The compressive interaction between the spiral or rib and grout provides the resistance for the rod. Thus, the radial shrinkage in these rods has a minor effect on the interfacial shear strength $\tau_{\mathrm{u}}$ and residual frictional stress $\tau_{\mathrm{s}}$. Therefore, the effect of the radial shrinkage in FRP rods should further be taken into 
Table 3 Interfacial parameters obtained from Zhang et al. [32]

\begin{tabular}{|c|c|c|c|c|c|}
\hline Type & No. & $\tau_{\mathrm{u}}(\mathrm{MPa})$ & $\tau_{\mathrm{s}}(\mathrm{MPa})$ & $\delta_{1}(\mathrm{~mm})$ & $\delta_{2}(\mathrm{~mm})$ \\
\hline Round sanded + CG1 & Specimen 1 & 8.2 & 2.8 & 1.31 & 3.86 \\
\hline Round sanded + CG2 & Specimen 2 & 7.9 & 2.5 & 1.05 & 6.10 \\
\hline Round sanded + CG3 & Specimen 3 & 8.4 & 3.1 & 0.72 & 5.60 \\
\hline Round sanded + CG4 & Specimens 4-6 & 8.7 & 2.6 & 0.66 & 4.18 \\
\hline Spiral wound + CG1 & Specimen 7 & 12.3 & 3.3 & 2.34 & 7.66 \\
\hline Spiral wound + CG2 & Specimen 8 & 7.9 & 2.4 & 2.30 & 6.48 \\
\hline Spiral wound + CG3 & Specimen 9 & 12.3 & 3.3 & 1.78 & 7.80 \\
\hline Spiral wound + CG4 & Specimens $10-12$ & 13.2 & 3.8 & 2.50 & 6.50 \\
\hline Indented + CG1 & Specimen 13 & 13.1 & 4.1 & 3.32 & 9.60 \\
\hline Indented + CG2 & Specimen 14 & 10.6 & 3.1 & 2.97 & 9.95 \\
\hline Indented + CG3 & Specimen 15 & 12.4 & 4.4 & 2.61 & 8.70 \\
\hline Indented + CG4 & Specimens 16-17 & 14.4 & 5.6 & 2.90 & 6.40 \\
\hline
\end{tabular}

Table 4 Comparison between analytical results and experimental results from Zhang et al. [32]

\begin{tabular}{llllc}
\hline $\begin{array}{l}\text { Numbers of } \\
\text { specimens }\end{array}$ & Types of Specimens & $P_{\max }^{\mathrm{a}}(\mathrm{kN})$ & $P_{\max }^{\mathrm{e}}(\mathrm{kN})$ & $\begin{array}{l}\left(P_{\max }^{\mathrm{e}}-P_{\max }^{\mathrm{a}}\right) / P_{\max }^{\mathrm{e}} \\
\times 100(\%)\end{array}$ \\
\hline 1 & Round sanded + CG1 & 18.8 & 19.4 & 3.1 \\
2 & Round sanded + CG2 & 18.3 & 18.6 & 1.6 \\
3 & Round sanded + CG3 & 19.5 & 19.9 & 2.0 \\
4 & Round sanded + CG4 & 20.0 & 20.6 & 2.9 \\
5 & Round sanded + CG4 & 36.9 & 26.9 & -37.2 \\
6 & Round sanded + CG4 & 51.9 & 37.1 & -39.9 \\
7 & Spiral wound + CG1 & 30.0 & 30.9 & 2.9 \\
8 & Spiral wound + CG2 & 19.4 & 20.0 & 3.0 \\
9 & Spiral wound + CG3 & 30.0 & 31.0 & 3.2 \\
10 & Spiral wound + CG4 & 31.8 & 33.3 & 4.5 \\
11 & Spiral wound + CG4 & 56.2 & 55.6 & -1.1 \\
12 & Spiral wound + CG4 & 74.5 & 67.9 & -9.7 \\
13 & Indented + CG1 & 32.3 & 32.6 & 0.9 \\
14 & Indented + CG2 & 26.2 & 26.7 & 1.9 \\
15 & Indented + CG3 & 30.6 & 30.8 & 0.6 \\
16 & Indented + CG4 & 35.3 & 35.8 & 1.4 \\
17 & Indented + CG4 & 68.0 & 67.6 & -0.6 \\
\hline
\end{tabular}

account in future studies to predict the maximum pull-out load more accurately.

The effect of the embedment length-to-rod diameter ratio on the distribution of interfacial shear stress in the ultimate state is shown in Figs. 7, 8 and 9 for three types of FRP rods, respectively. From Figs. 7 to 9, it can be seen that the smaller the embedment length-to-rod diameter ratio is, the more uniform is the interfacial shear stress. When the embedment length is equal to $100 \mathrm{~mm}(L / D=13.3,12.7$ or $12.5)$, the variation of the interfacial shear stress is small. In this case, the interfacial shear stress can be assumed to be uniform as by Zhang et al. [32] and the corresponding interfacial parameters obtained from specimens with embedment length $100 \mathrm{~mm}$ are reliable.

To further verify the proposed analytical solution, the data by Zhang and Benmokrane [30] are selected 
Fig. 7 Distribution of interfacial shear stress along the length of the sand rounded FRP rod

Fig. 8 Distribution of interfacial shear stress along the length of the spiral wound FRP rod
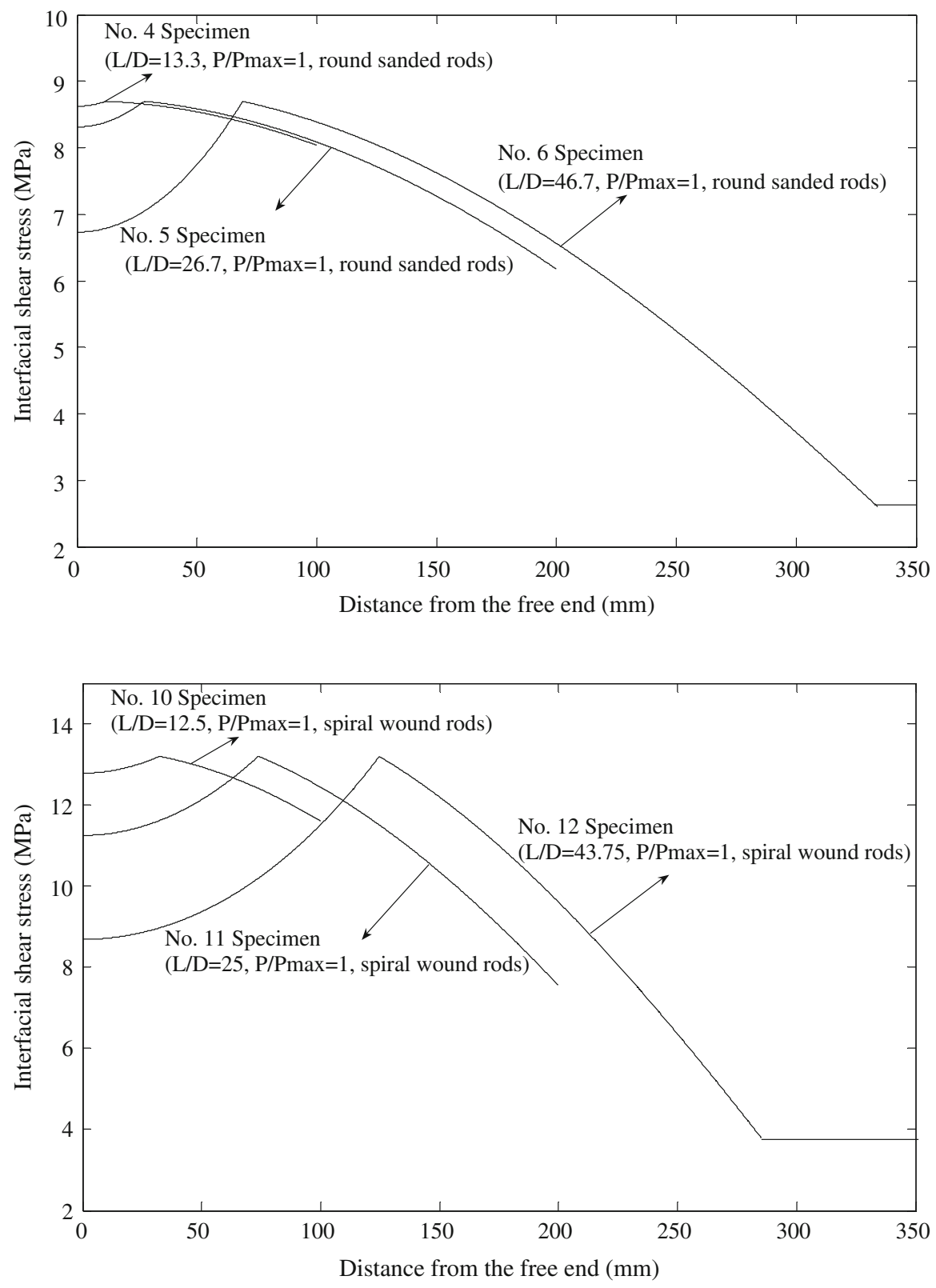

for comparison. The main difference compared with the first series of data [32] is that the present grout thickness $t$ is much lower as shown in Table 5. The adopted specimens are composed of two types of FRP rods classified as round sanded and ribbed, and two types of cement grouts denoted as CM and EM as shown in Table 6. For each test, the interfacial parameters are selected from the specimens with embedment length of $40 \mathrm{~mm}(D=7.5$ and $7.9 \mathrm{~mm})$ as shown in Table 7.
It can be seen from Table 8 that, except for the No. SP2 specimen, the calculated results are in good agreement with the experimental results. For the No. SP2 specimen, the surface of the FRP rod is round sanded and its bond mechanism with the grout is friction-resistance type. Since the elastic modulus of the rod is relatively low $(60.8 \mathrm{GPa})$, the effect of the radial shrinkage in the rod becomes more significant due to the larger maximum pull-out strain as explained above for Nos. 5 and 6 specimens. 
Fig. 9 Distribution of interfacial shear stress along the length of the indented FRP rod

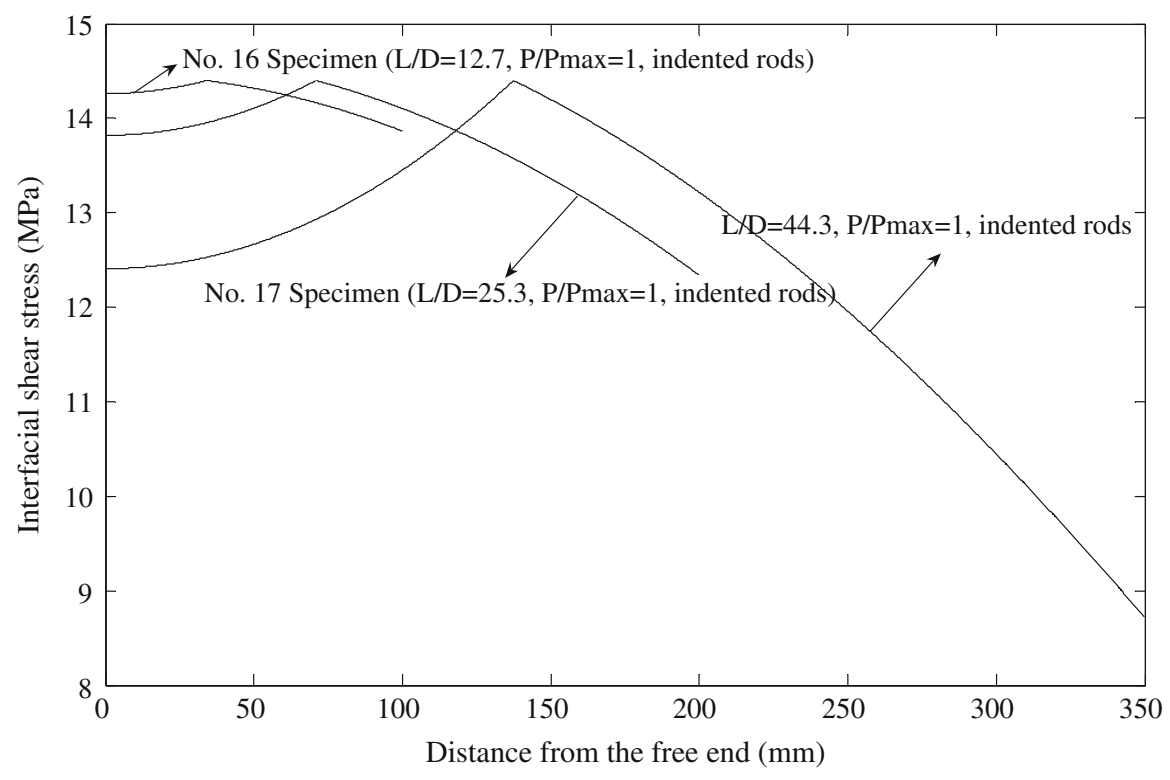

Table 5 Basic geometrical and mechanical parameters of anchorage specimens from Zhang and Benmokrane [30]

\begin{tabular}{lllllllllc}
\hline $\begin{array}{l}\text { Numbers of } \\
\text { specimens }\end{array}$ & Types of specimens & $D(\mathrm{~mm})$ & $t(\mathrm{~mm})$ & $b(\mathrm{~mm})$ & $L(\mathrm{~mm})$ & $E_{\mathrm{c}}(\mathrm{GPa})$ & $\begin{array}{l}\text { Poisson's ratio } \\
\text { of grout }\end{array}$ & $E_{\mathrm{p}}(\mathrm{GPa})$ & $E_{\mathrm{s}}(\mathrm{GPa})$ \\
\hline SP1 & Round sanded + EM & 7.5 & 8.95 & 4.8 & 40 & 22.6 & 0.24 & 60.8 & 195 \\
SP2 & Round sanded + EM & 7.5 & 8.95 & 4.8 & 80 & 22.6 & 0.24 & 60.8 & 195 \\
SP3 & Ribbed + CM & 7.9 & 8.75 & 4.8 & 40 & 26.6 & 0.22 & 163.3 & 195 \\
SP4 & Ribbed + CM & 7.9 & 8.75 & 4.8 & 80 & 26.6 & 0.22 & 163.3 & 195 \\
SP5 & Ribbed + EM & 7.9 & 8.75 & 4.8 & 40 & 22.6 & 0.24 & 163.3 & 195 \\
SP6 & Ribbed + EM & 7.9 & 8.75 & 4.8 & 80 & 22.6 & 0.24 & 163.3 & 195 \\
\hline
\end{tabular}

Table 6 Mixture proportions of grout $\mathrm{CM}$ and EM from Zhang and Benmokrane [30]

\section{Type Mixture proportions}

CM Type 10 SF cement (Blended Type I cement containing $8 \%$ silica fume) + sand (50\% by weight of cement $)+$ superplasticizer solids $(1.0 \%$ by weight of cement)

EM Type $10 \mathrm{SF}$ cement (Blended Type I cement containing $8 \%$ silica fume) + sand (50\% by weight of cement $)+$ superplasticizer solids $(1.0 \%$ by weight of cement $)+$ swelling agent $(0.005 \%$ by weight of cement $)$

Table 7 Interfacial parameters obtained from Zhang and Benmokrane [30]

\begin{tabular}{llllll}
\hline Types of specimens & Corresponding specimens & $\tau_{\mathrm{u}}(\mathrm{MPa})$ & $\tau_{\mathrm{s}}(\mathrm{MPa})$ & $\delta_{1}(\mathrm{~mm})$ & $\delta_{2}(\mathrm{~mm})$ \\
\hline Round sanded + EM & Specimens SP1 and SP2 & 14.85 & 3.93 & 1.22 & 3.25 \\
Ribbed + CM & Specimens SP3 and SP4 & 23.75 & 6.78 & 4.49 & 8.99 \\
Ribbed + EM & Specimens SP5 and SP6 & 21.54 & 8.06 & 4.22 & 7.89 \\
\hline
\end{tabular}


Table 8 Comparison between analytical results and experimental results from Zhang and Benmokrane [30]

\begin{tabular}{|c|c|c|c|c|}
\hline $\begin{array}{l}\text { Numbers of } \\
\text { specimens }\end{array}$ & Types of specimens & $P_{\max }^{\mathrm{a}}(\mathrm{kN})$ & $P_{\max }^{\mathrm{e}}(\mathrm{kN})$ & $\begin{array}{l}\left(P_{\max }^{\mathrm{e}}-P_{\max }^{\mathrm{a}}\right) / P_{\max }^{\mathrm{e}} \\
\times 100(\%)\end{array}$ \\
\hline SP1 & Round sanded + EM & 13.8 & 14.0 & 1.4 \\
\hline SP2 & Round sanded + EM & 26.7 & 20.3 & -31.5 \\
\hline SP3 & Ribbed $+\mathrm{CM}$ & 23.5 & 23.6 & 0.4 \\
\hline SP4 & Ribbed $+\mathrm{CM}$ & 46.6 & 45.5 & -2.4 \\
\hline SP5 & Ribbed + EM & 21.3 & 21.4 & 0.5 \\
\hline SP6 & Ribbed + EM & 42.3 & 37.0 & -14.3 \\
\hline
\end{tabular}

\section{Conclusions}

An analytical solution has been presented for predicting the maximum pull-out load of FRP rods embedded in steel tubes filled with cement grout. In the proposed solution, four parameters concerning the rod-grout interface, i.e., the interfacial shear strength, the slip corresponding to the shear strength, the residual frictional stress and the slip when the residual frictional stress first occurs, are needed. The shear stress along the thickness direction of the grout layer, the tensile stress in the rod and the interfacial shear stress at the rod-grout interface have been derived in an analytical manner. By modeling interfacial debonding as an interfacial shear crack, the pull-out load has been expressed as a function of the interfacial crack length. With the help of the Lagrange multiplier method, the maximum pull-out load has been determined. By comparing the analytical solution with the experimental results obtained from literature, it can be concluded that it can predict the maximum pull-out load of spiral wound and indented rods embedded in steel tubes filled with cement grout with reasonable accuracy. But for the rod with round sanded surface and low elastic modulus, the proposed solution seems inapplicable at the present stage. Besides, the proposed model can be in principle extended to reinforced concrete, to predict the pull-out capacity of a steel bar. It is mainly because that the concrete Poisson's ratio is much smaller than that of the polymeric rods and the shear-lag model is also applicable.

Acknowledgment The financial support from the National Natural Science Foundation with Grant No. 50578025, of the People's Republic of China, is greatly acknowledged.
Open Access This article is distributed under the terms of the Creative Commons Attribution Noncommercial License which permits any noncommercial use, distribution, and reproduction in any medium, provided the original author(s) and source are credited.

\section{References}

1. Bamonte P, Coronelli D, Gambarova PG (2003) Smooth anchored bars in NSC and HPC: a study on size effect. J Adv Concr Technol 1(1):42-53. doi:10.3151/jact.1.42

2. Benmokrane B (1994) Grouted anchorages for aramid fiber reinforced plastic prestressing tendons. Can J Civ Eng 21:713-715 discussion

3. Benmokrane B, Chennouf A (1997) Pull-out of behavior of FRP ground anchors. Int SAMPE Symp Exhib Proc 42(1): 311-324

4. Benmokrane B, Xu HX, Bellavance E (1996) Bond strength of cement grouted glass fiber reinforced plastic (GFRP) anchor bolts. Int J Rock Mech Min Sci 33(5):455465. doi:10.1016/0148-9062(96)00006-X

5. Benmokrane B, Zhang BR, Chennouf A (2000) Tensile properties and pull-out behavior of AFRP and CFRP rods for grouted anchor applications. Constr Build Mater 14(3):157-170. doi:10.1016/S0950-0618(00)00017-9

6. Benmokrane B, Zhang BR, Chennouf A, Masmoudi R (2000) Evaluation of aramid and carbon fibre reinforced polymer composite tendons for prestressed ground anchors. Can J Civ Eng 27(5):1031-1045. doi:10.1139/cjce-27-51031

7. Budelmann H, Kepp B, Rostasy FS (1990) Fatigue behavior of bond-anchored unidirectional glass-FRP's. In: Serviceability and durability of construction materials: proceedings of the first materials engineering congress, pp 1142-1151

8. Chennouf A, Benmokrane B (1997) Tensile properties and pull-out behavior of fiber reinforced plastic ground anchors. Proc Annu Conf Can Soc Civ Eng 6:141-150

9. Erki MA, Rizkalla SH (1993) FRP reinforcements for concrete structures. Concr Int Des Constr 15(6):48-53

10. Erki MA, Rizkalla SH (1993) Anchorages for FRP reinforcement. Concr Int Des Constr 15(6):54-59 
11. FIB (2000) In: Tepfers R (ed) State-of-art report on "bond of reinforcement in concrete" (Bulletin No. 10). FIB, $427 \mathrm{pp}$

12. Gao Y, Mai Y, Cotterell B (1988) Fracture of fiber-reinforced materials. Z Angew Math Phys 39(4):550-572. doi: 10.1007/BF00948962

13. Gray RJ (1984) Analysis of the effect of embedded fibre length on fibre debonding and pull-out from an elastic matrix. Part 1. Review of theories. J Mater Sci 19(3):861870. doi:10.1007/BF00540456

14. Hsueh CH (1988) Elastic load transfer from partially embedded axially loaded fibre to matrix. J Mater Sci Lett 7(5):497-500. doi:10.1007/BF01730704

15. Hsueh CH (1990) Interfacial debonding and fiber pull-out stresses of fiber-reinforced composites. Mater Sci Eng A: Strut Mater: Properties Microstruct Process A123(1):1-11

16. Hsueh CH (1994) Consideration of radial dependences of axial stresses in the shear-lag model for fibre pull-out. $\mathbf{J}$ Mater Sci 29(7):1801-1806. doi:10.1007/BF00351299

17. Hsueh CH, Becher PF (1998) Interfacial shear debonding problems in fiber-reinforced ceramic composites. Acta Mater 46(9):3237-3245. doi:10.1016/S1359-6454(98) 00008-1

18. Karbhari VM, Wilkins DJ (1990) A theoretical model for fiber debonding incorporating both interfacial shear and frictional stresses. Scr Metall Mater 24(7):1197-1202. doi: 10.1016/0956-716X(90)90327-D

19. Li VC, Chan YW (1994) Determination of interfacial debond mode for fiber-reinforced cementitious composites. J Eng Mech 120(4):707-719. doi:10.1061/(ASCE)0733-9399 (1994)120:4(707)

20. Li Z, Xu M, Chui NC (1998) Enhancement of rebar (smooth surface) - concrete bond properties by matrix modification and surface coatings. Mag Concr Res 50(1): 49-57

21. Liu H, Zhang X, Mai Y, Diao X (1999) On steady-state fibre pull-out II: computer simulation. Compos Sci Technol 59(15):2191-2199. doi:10.1016/S0266-3538(99)00060-3

22. Mckay KS, Erki MA (1993) Grouted anchorages for aramid fiber reinforced plastic prestressing tendons. Can J Civ Eng 20(6):1065-1069

23. Mochida S, Tanaka T, Yagi K (1992) The development and application of a ground anchor using new materials. In:
Proceedings of the 1 st international conference on advanced. composite materials in bridges and structures, pp 393-401

24. Morrison JK, Shah SP, Jenq YS (1988) Analysis of fiber debonding and pull-out in composites. J Eng Mech 114(2): 277-294. doi:10.1061/(ASCE)0733-9399(1988)114:2(277)

25. Naaman AE, Namur GG, Alwan JM, Najm HS (1991) Fiber pull-out and bond slip. I: Analytical study. J Struct Eng 117(9):2769-2790. doi:10.1061/(ASCE)0733-9445(1991) 117:9(2769)

26. Naaman AE, Namur GG, Alwan JM, Najm HS (1991) Fiber pull-out and bond slip. II: Experimental validation. J Struct Eng 117(9):2791-2800. doi:10.1061/(ASCE)0733-9445 (1991)117:9(2791)

27. Nanni A, Tomas J (1996) Grouted anchors for carbon FRP tendon. Proc Mater Eng Conf 1:527-534

28. Ouyang C, Pacios A, Shah SP (1994) Pull-out of inclined fibers from cementitious matrix. J Eng Mech 120(12): 2641-2659. doi:10.1061/(ASCE)0733-9399(1994)120:12 (2641)

29. Stang H, Li Z, Shah SP (1990) Pull-out problem: stress versus fracture mechanical approach. J Eng Mech 116(10): 2136-2150. doi:10.1061/(ASCE)0733-9399(1990)116:10 (2136)

30. Zhang BR, Benmokrane B (2002) Pull-out bond properties of fiber-reinforced polymer tendons to grout. J Mater Civ Eng 14(5):399-408. doi:10.1061/(ASCE)0899-1561(2002) $14: 5(399)$

31. Zhang X, Liu H, Mai Y, Diao X (1999) On steady-state fibre pull-out I: the stress field. Compos Sci Technol 59(15):2179-2189. doi:10.1016/S0266-3538(99)00110-4

32. Zhang BR, Benmokrane B, Chennouf A (2000) Prediction of tensile capacity of bond anchorages for FRP tendons. J Compos Constr ASCE 4(2):39-47. doi:10.1061/(ASCE) 1090-0268(2000)4:2(39)

33. Zhang BR, Benmokrane B, Chennouf A, Mukhopadhyaya P, EI-Safty A (2001) Tensile behavior of FRP tendons for prestressed grouted anchors. J Compos Constr ASCE 5(2): $85-93$

34. Zhang BR, Benmokrane B, Ebead U (2006) Design and evaluation of fiber-reinforced polymer bond-type anchorages and ground anchors. Int J Geomech 6(3):166-175. doi:10.1061/(ASCE)1532-3641(2006)6:3(166) 